\title{
Net energy metering scheme based on time of use pricing for residents in Malaysia
}

\author{
Abdul Hafiz Razali, Md Pauzi Abdullah, Mohammad Yusri Hassan, Dalila Mat Said, \\ Faridah Hussin \\ Centre of Electrical Energy System (CEES), School of Electrical Engineering, Faculty of Engineering, Universiti \\ Teknologi Malaysia (UTM), Malaysia
}

\begin{tabular}{l} 
Article Info \\
\hline Article history: \\
Received Feb 1, 2020 \\
Revised Mar 29, 2020 \\
Accepted Apr 5, 2020 \\
\hline Keywords: \\
Net energy metering \\
Photovoltaic \\
Residential \\
Time-of-use
\end{tabular}

\begin{abstract}
The current Malaysia's net energy metering (NEM) scheme has been updated in 2019 that credits excess generation into the next billing month at retail rate compare to at displaced cost. The new NEM may attract more installation of solar photovoltaic (PV) system among residential customers. However, it is discovered that customers with low monthly electricity consumptions are still not benefited since their electricity cost is lower than the PV generation cost. Implementing time-of-use (TOU) pricing on NEM scheme may overcome the problem as it based on hourly energy usage. This paper compares the annualized energy cost of residential PV system under different TOU prices and NEM scheme. The results show that an optimized TOU prices as suggested in this paper may give financial benefits to all residential customers with PV system, including the one with low monthly consumption.
\end{abstract}

Copyright $\odot 2020$ Institute of Advanced Engineering and Science. All rights reserved.

\section{Corresponding Author:}

Md Pauzi Abdullah,

Centre of Electrical Energy Systems (CEES),

School of Electrical Engineering,

Faculty of Engineering,

Universiti Teknologi Malaysia (UTM),

81310 Skudai, Johor, Malaysia.

Email: pauzi@fke.utm.my

\section{INTRODUCTION}

In Malaysia, as compared to previous feed-in tariff (FIT) scheme, net energy metering (NEM) scheme is less popular among residential customers since they only get paid if their PV generation is higher than their consumption [1]. This condition is very unlikely to happen since the electricity output from residential PV panel is commonly small due to small PV size. The customers only gain benefit from the lower electricity bill due to the lower $\mathrm{kWh}$ consumption (due to net consumption). In other words, net metering can avoid customers from being charged the expensive electricity tariff block. If the monthly $\mathrm{kWh}$ consumption of a customer is already low, NEM will not give financial benefit to that customer since them already being charged with low tariff. The work in [1-2] highlighted the disadvantage of the current NEM scheme on residential customers with low monthly energy usage. The problem can be solved by implementing time-based electricity tariff for charging the customers and rewarding PV generations.

Time-of-use (TOU) tariff is an electricity price scheme in which the customer is charged base on the time they used the electricity [3]. Basically, the price will be expensive at periods with high electricity demands and cheap at periods with low demand. The prices for those periods are pre-established and make known to the customers in advance, allowing them to adjust their electricity usage in response to such prices. In Malaysia, TOU is applied on commercial and industrial customers [4-5].Applying TOU pricing on NEM scheme will benefit customers since the TOU prices is high at noon where the output from the PV panel is also high. Through TOU, the PV energy price can be valued more correctly [6]. However, determining the 
the right TOU prices is critical as it will affect financial returns of both customers and utilities [7]. This paper will investigate the annualized energy cost of different TOU prices on residential customers under Malaysia's NEM scheme. The results will also be compared with the existing NEM 2019 scheme as well as energy cost without PV system.

\section{NET ENERGY METERING SCHEME}

Net energy metering (NEM) allows a consumer to generate, use and sell only the excess energy to the grid. The main objective of NEM is for self-consumption to reduce demand from the grid [8]. A bidirectional meter will be installed that able to show the direction of energy usage [9]. If the meter rotates forward, it means that the customser is getting energy from the grid. In contrary, if the meter rotates backwards, it means the customer is supplying energy to the grid. Any excess generation after billing period will be given as credits. These credit is used to offset the electricity bill [10]. The maximum roll over credits period is 12 or 24 months [11-12]. Depending on countries, the remaining credits either will be paid to customer or will be set to zero [13-14]. Indirectly, the policy has made the grid act as a very huge storage [15].

A well-designed NEM policy provides a simple, low cost, and easily administered way to deal with PV residential system. NEM overcome the complexity of Feed-in tariff (FIT) scheme that requires a contract and installation of two meters. Inflation is another disadvantage of FIT scheme, since the customers may need to pay higher electricity rate in the future but not for FIT rate paid to them [16]. NEM acts like a perfect hedge against electricity prices rise [17]. In addition, NEM able to reduce power losses [18] by allowing the customers to consume the generated energy first and only export the excess energy instead of export all the generated. It will prevent congestion in the transmission lines that causes rise in power losses. However, NEM requires longer years for return of investment compared to FIT. A study presented in [19] shows the NEM will takes 16.1 years compared to 11.5 years for FIT. Next, some countries are implementing increasing-block rate tariff, which means the electricity rate per $\mathrm{kWh}$ increases as the volume of consumption increases. Thus NEM will not necessarily mean a profitable investment, especially for small consumers if the first electricity tariff block is comparatively low [15].

\subsection{NEM in Malaysia}

In Malaysia, NEM was firstly introduced in 2016 replacing the FIT scheme. The scheme has been revised and a new NEM is introduced in 2019. There is small but significant difference between the NEM introduced in 2016 (refered as NEM 2016) and the one introduced in 2019. For NEM 2016, solar energy is eligible for all type of consumer. For residential, the allowable capacity is up to $12 \mathrm{~kW}$ for single phase and $72 \mathrm{~kW}$ for three phases. While for commercial and industrial, it is up to $1 \mathrm{MW}$. The excess generation will be credited into next billing period at a displaced cost [20]. The maximum roll over period is 24 months and any surplus after 24 months will be forfeited [21-22]. The electricity bill under NEM 2016 scheme is equal to the consumption price minus the generation price in a month. While, the consumption price is equal to total consumption times with Tariff A (domestic tariff) as in Table 1 and generation price is equal to total generation times with displaced cost. For NEM 2019, the allowable customers are residential, commercial, industrial and agriculture. The excess generation will be credited into the next bill period at retail rate (Tariff Adomestic tariff) [23] as given in Table 1. The rest is still the same as NEM 2016 scheme. For NEM 2019, the calculation of electricity bill is simple. The net consumption is equal to the total consumption minus the total generation. Then, the electricity bill is calculated by multiplying the net consumption to Tariff A (domestic tariff).

Table 1. Peninsular Malaysia's electricity tariff for domestic customers

\begin{tabular}{cc}
\hline Tariff Category $(\mathrm{kWh})$ & Unit price $(\mathrm{sen} / \mathrm{kWh})$ \\
\hline $1-200$ & 21.80 \\
$201-300$ & 33.40 \\
$301-600$ & 51.60 \\
$601-900$ & 54.60 \\
$>900$ & 57.10 \\
\hline
\end{tabular}

\subsection{Impact of NEM 2019 on small residential customer}

Even though NEM 2019 overcome some weakneses of NEM 2019, small resident customers still do not benefit from the scheme for all PV system size. The main factor is small residential customers are being charged with low electricity tariff rates. In Malaysia, residential customers are based on increasing block tariff structure as shown in Table 2 . For the first $200 \mathrm{kWh}$ consumption, they only pay $21.8 \mathrm{cents} / \mathrm{kWh}$. The price is comparatively low compared to the PV energy cost, thus it does not viable financially to install

Net energy metering scheme based on time of use pricing for residents in Malaysia (Abdul Hafiz Razali) 
the PV system that requires high capital and maintenance cost. For medium and large residential customers, which consumed more than $300 \mathrm{kWh}$ a month, they are paying more expensive electricity rates, which is higher than the cost of energy from the PV panel.

\section{PROPOSED TOU-NEM SCHEME}

The purpose of this research is to overcome the weakness of existing NEM scheme which is not benefited for small size residents by proposing the existing NEM scheme is integrated with the TOU pricing scheme. The main idea of TOU-NEM scheme is to give the residents higher returns so all the residents size will benefit from the scheme, especially for small size residents. Since TOU structure charged at higher rates on peak hours, which means in daytime, meanwhile solar energy also generated at the same time. Therefore, the solar energy will be generated and offset the bill at higher rates.

\subsection{Mathematical formulation}

For the NEM-TOU method, the net consumption is calculated hourly instead of monthly, where the electricity bill is then calculated on hourly basis by multiplying the net consumption of a particular hour with the time of use (TOU) tariff for that hour. If the electricity consumption is higher than generation, the net consumption will be positive and electricity bill will also be positive. It indicates the amount of electricity bill that the consumer should pay for that hour. On the other hand, if the electricity consumption is lower than generation, the net consumption will be negative and the electricity bill will also be negative. The negative sign indicates that the utility need to pay the consumer for that hour. It can be mathematically presented as follows;

$$
\begin{aligned}
& \text { at hour 1: } \quad P_{\text {hour } 1}^{\text {net }}=P_{\text {hour } 1}^{\text {consump }}-P_{\text {hour } 1}^{\text {generation }}, E B_{\text {hour } 1}=P_{\text {hour } 1}^{\text {net }} \times \text { TOU } \\
& \text { hour } 1 \\
& \text { at hour 2: } \quad P_{\text {hour } 2}^{\text {net }}=P_{\text {hour } 2}^{\text {consump }}-P_{\text {hour } 2}^{\text {generation }}, E B_{\text {hour } 2}=P_{\text {hour } 2}^{\text {net }} \times \text { TOU } \\
& \text { hour } 2 \\
& \text { at hour 24: } \quad P_{\text {hour } 24}^{\text {net }}=P_{\text {hour } 24}^{\text {consump }}-P_{\text {hour } 24}^{\text {generation }}, E B_{\text {hour } 24}=P_{\text {hour } 24}^{\text {net }} \times \operatorname{TOU}_{\text {hour } 24}
\end{aligned}
$$

Thus, the total electricity bill for one month can be formulated as follows;

$$
E B^{\text {month }}=\sum_{d=1}^{30} \sum_{h=1}^{24}\left(P_{d, h}^{\text {consump }}-P_{d, h}^{\text {generation }}\right) \times T O U_{d, h}
$$

where,

$\begin{array}{ll}P_{\text {hour hump }}^{\text {cons }} & : \text { Electricity consumption at at hour } h \\ P_{\text {houration }}^{\text {geur } h} & : \text { Electricity generation at at hour } h \\ P_{\text {hour } h}^{\text {net }} & : \text { Net consumption at hour } h \\ \text { EB } & : \text { Electricity bill } \\ \text { TOU }_{d, h} & : \text { Time-of-use tariff of day } d \text { at hour } h \\ \text { TOU }_{d, h} & : \text { Time-of-use tariff of day } d \text { at hour } h\end{array}$

To simplify the problem, in this paper it is assumed that daily load profile pattern and PV output pattern are approximately the same. Thus, the total electricity bill for one year can be approximated as follows;

$$
E B^{\text {year }}=\left(\sum_{d=1}^{30} \sum_{h=1}^{24}\left(P_{d, h}^{\text {consump }}-P_{d, h}^{\text {generation }}\right) \times T O U_{d, h}\right) \times 12
$$

Since the electricity bill is calculated for 25 years, the present cost will take in consideration [24]. Assume that the discounted value is 6\% every year [25]. It can be mathematically presented as follows;

$$
\begin{aligned}
& \text { at year 1: } E B_{\text {year } 1}=\text { Electricity bill in one year } \times \frac{1}{1.06^{0}} \\
& \text { at year 2: } E B_{\text {year } 2}=\text { Electricity bill in one year } \times \frac{1}{1.06^{1}} \\
& \text { at year 25: } E B_{\text {year } 25}=\text { Electricity bill in one year } \times \frac{1}{1.06^{24}}
\end{aligned}
$$


Thus, the total electricity bill for 25 years can be formulated as follows;

$$
\begin{aligned}
& E B^{25} \text { years }= \\
& \sum_{n=1}^{25}\left[\left(\sum_{d=1}^{30} \sum_{h=1}^{24}\left(P_{d, h}^{\text {consump }}-P_{d, h}^{\text {generation }}\right) \times T O U_{d, h}\right) \times 12\right] \times \frac{1}{1.06^{n-1}}
\end{aligned}
$$

Therefore, the annualized cost for the total electricity bill under proposed TOU-NEM scheme for 25 years can be formulated as follows [26];

$$
\operatorname{Cost}_{T O U-N E M}^{\text {annualized }}=E B^{25} \text { years } \times 78.227 \times 10^{-3}
$$

\subsection{Optimized TOU-NEM formulation}

The objective is to maximize the cost savings to ensure the small residents able to reduce the electricity bills. Therefore, the objective function can be written as follows;

$$
\text { Max\{Cost Savings\} }
$$

where the cost saving can be formulated as follows;

$$
\text { Cost Savings }=\text { Cost }_{\text {existing }}^{\text {annualized }}-\operatorname{Cost}_{T O U-N E M}^{\text {annualized }}-\operatorname{Cost}_{P V}^{\text {annualized }}
$$

Therefore, the objective fuction can be written as follows;

$$
\operatorname{Max}\left\{\operatorname{Cost}_{\text {existing }}^{\text {annualized }}-\operatorname{Cost}_{T O U-N E M}^{\text {annualized }}-\operatorname{Cost}_{P V}^{\text {annualized }}\right\}
$$

Since annualized cost of existing tariff ( $\left.\operatorname{Cost}_{\text {existing }}^{\text {annualized }}\right)$ and PV cost ( $\left.\operatorname{Cost}_{P V}^{\text {annualized }}\right)$ are constant, therefore, to maximize the cost savings, the annualized cost of TOU-NEM ( $\left.\operatorname{Cost}_{\text {TOU }-N E M}^{\text {annulized }}\right)$ should be smallest possible. Therefore, the objective function can be written as follows:

$$
\operatorname{Min}\left\{\operatorname{Cost}_{T O U-N E M}^{\text {annualized }}\right\}
$$

\section{CASE STUDY}

In this paper, the TOU structure is based on Malaysia's enhanced time of use (ETOU) tariff. Under this scheme, there will be three time zones energy charges; i) peak, ii) mid-peak and iii) off-peak rates. The rates will be applied on a daily basis including weekends for year-round. The off-peak rate starts from $10 \mathrm{pm}$ to $8 \mathrm{am}$, while mid-peak rate has two different time from $8 \mathrm{am}$ to $11 \mathrm{am}$ and $5 \mathrm{pm}$ to $10 \mathrm{pm}$. The peak rate starts from $11 \mathrm{am}$ to $5 \mathrm{pm}$. The load profile of small residential customer with $2 \mathrm{kWp}$ PV system in [27] is used. Table 2 shows the TOU prices limits between maximum and minimum for four TOU schemes. For TOU 1, the minimum TOU price has been set at 5 cents. While, the value of 10 cents, 15 cents and 20 cents have been set for TOU 2, TOU 3 and TOU 4 respectively. The mid-peak rate value is exactly between peak and off-peak rates. The equality constraint annualized cost of existing tariff and TOU rates (without PV) has been set to get the optimized TOU rates result.

Table 3 shows the optimized TOU rates results from (14). For TOU 1, the rate for off-peak period is 10 cents, while mid-peak is 11 cents and peak is RM1. Meanwhile for TOU 2, the off-peak rate is 20 cents, the mid-peak rate is 22 cents and the peak rate is 90 cents. Under TOU 3 tariff, the rate on off-peak period is 30 cents, 33 cents at mid-peak and 80 cents at peak period. For TOU 4 tariff, the rate on off-peak period is 40 cents, while on mid-peak is 44 cents and on peak is 70 cents.

Table 2. TOU inequaity constraint prizes for the optimization problem

\begin{tabular}{ccc}
\hline TOU & Min & Max \\
\hline TOU 1 & 0.05 & 0.9 \\
TOU 2 & 0.10 & 0.9 \\
TOU 3 & 0.15 & 0.9 \\
TOU 4 & 0.20 & 0.9 \\
\hline
\end{tabular}


Table 3. Optimized TOU prices for 24 hours

\begin{tabular}{cccccc}
\hline Type & Hour & TOU 1 & TOU 2 & TOU 3 & TOU 4 \\
\hline Off- peak & 0 & 0.0500 & 0.1000 & 0.1500 & 0.2000 \\
& 1 & 0.0500 & 0.1000 & 0.1500 & 0.2000 \\
& 2 & 0.0500 & 0.1000 & 0.1500 & 0.2000 \\
& 3 & 0.0500 & 0.1000 & 0.1500 & 0.2000 \\
& 4 & 0.0500 & 0.1000 & 0.1500 & 0.2000 \\
Mid-peak & 5 & 0.0500 & 0.1000 & 0.1500 & 0.2000 \\
& 6 & 0.0500 & 0.1000 & 0.1500 & 0.2000 \\
& 7 & 0.0500 & 0.1000 & 0.1500 & 0.2000 \\
Peak & 9 & 0.2942 & 0.2852 & 0.2762 & 0.2672 \\
& 10 & 0.2942 & 0.2852 & 0.2762 & 0.2672 \\
& 11 & 0.5385 & 0.4704 & 0.4024 & 0.3344 \\
& 13 & 0.5385 & 0.4704 & 0.4024 & 0.3344 \\
& 14 & 0.5385 & 0.4704 & 0.4024 & 0.3344 \\
& 15 & 0.5385 & 0.4704 & 0.4024 & 0.3344 \\
& 16 & 0.5385 & 0.4704 & 0.4024 & 0.3344 \\
Mid-peak & 17 & 0.2942 & 0.2852 & 0.2762 & 0.2672 \\
& 18 & 0.2942 & 0.2852 & 0.2762 & 0.2672 \\
& 19 & 0.2942 & 0.2852 & 0.2762 & 0.2672 \\
& 20 & 0.2942 & 0.2852 & 0.2762 & 0.2672 \\
& 21 & 0.2942 & 0.2852 & 0.2762 & 0.2672 \\
Off-peak & 22 & 0.0500 & 0.1000 & 0.1500 & 0.2000 \\
& 23 & 0.0500 & 0.1000 & 0.1500 & 0.2000 \\
\hline
\end{tabular}

Figure 1 shows the annualized cost for NEM2019 and various TOU-NEM schemes. The annualized cost for system without PV is included as a benchmark to compare the other schemes. From the figure, if no PV is installed, the annualized energy cost is RM 981.32. The NEM 2019 produces the cost at RM 1,171.58 higher than existing tariff which means the resident will suffer a loss $19.39 \%$ by investing in NEM2019. While, TOU-NEM 1, 2 and 3 produce lower than existing tariff at RM 927.85 and save at 5.45\%. At the same time, TOU-NEM 4 produce higher than existing tariff at RM 1,056.36 (loss 7.65\%) but lower than NEM2019. It can be seen that TOU-NEM 1, 2 and 3 give the same result since under the current NEM scheme, any excess generation will be credited into the next bill at a maximum roll over period of 24 months and any surplus after that will be forfeited. If the excess generation is paid by the utility, the annualized cost for NEM2019 and various optimized TOU-NEM schemes are lower as given in Figure 2. It could be said that TOU-NEM 1 produces the lowest cost at RM 637.98 and save 34.99\% followed by TOU-NEM 2 and 3 at RM 777.44 (save 20.78\%) and RM 916.90 (save 6.57\%) respectively. Only NEM-TOU 4 produce higher cost than existing tariff at RM 1,056.36 (loss 7.65\%). The results show that the proposed TOU-NEM scheme able to lower the annualized cost compared to existing tariff. Since the TOU structure will charge higher rates at peak hours, therefore it gives the advantage for PV generation that will generate at peak hours. Based on result, small resident able to get benefit from the proposed TOU-NEM scheme.

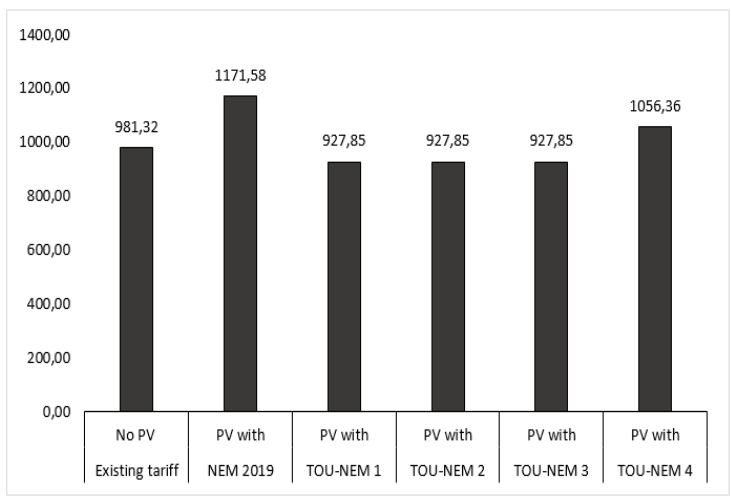

Figure 1. Annualized cost for different scheme (given as credits-24 months roll over period period)

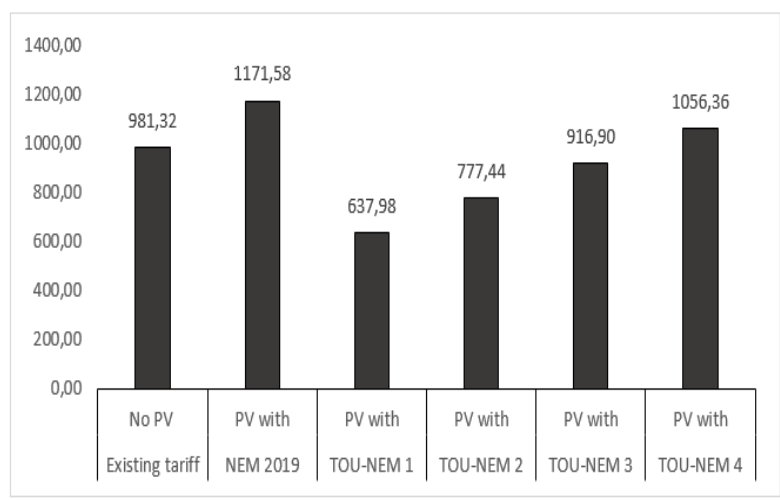

Figure 2. Annualized cost for different scheme (get paid for energy excess) 


\section{CONCLUSION}

The results presented in this paper have proved that by implementing TOU pricing on the current NEM scheme may reduce the annualize electricity cost of small customers that install PV system. It overcome the imperfection of the current NEM scheme that only benefitted large customers. Also, through TOU the generation price of PV system can be valued more correctly compare to the current flat price.

\section{REFERENCES}

[1] A. H. Razali, M. P. Abdullah, M. Y. Hassan, D. M. Said, and F. Hussin, "Integration of time of use (TOU) tariff in net energy metering (NEM) scheme for electricity customers," Indonesian Journal of Electrical Engineering and Informatics (IJEEI), vol. 7, no. 2, pp. 255-262, 2019.

[2] A. H. Razali, M. P. Abdullah, M. Y. Hassan, and F. Hussin, "Comparison of New and Previous Net Energy Metering (NEM) Scheme in Malaysia," ELEKTRIKA-Journal of Electrical Engineering, vol. 18, no. 1, pp. 36-42, 2019.

[3] M. P. Abdullah, N. S. M. Nazar, M. Y. Hassan, and F. Hussin, "Optimizing time of use (ToU) electricity pricing in regulated market," Jurnal Teknologi, vol. 78, no. 5-7, pp. 49-54, 2016.

[4] N. A. M. Azman, M. P. Abdullah, M. Y. Hassan, D. M. Said, and F. Hussin, "Enhanced Time of Use Electricity Pricing for Industrial Customers in Malaysia," Indonesian Journal of Electrical Engineering and Computer Science, vol. 6, no. 1, pp. 155-160, 2017.

[5] N. A. M. Azman et al., "Impact of Different Time of Use Electricity Pricing Structure on Residential Consumer," Indonesian Journal of Electrical Engineering and Computer Science, vol. 10, no. 3, pp. 1053-1060, 2018.

[6] N. Nazar, M. Abdullah, M. Hassan, and F. Hussin, "Time-based electricity pricing for Demand Response implementation in monopolized electricity market," in 2012 IEEE Student Conference on Research and Development (SCOReD), Pulau Pinang, pp. 178-181, 2012.

[7] N. S. Hussin, M. P. Abdullah, A. I. M. Ali, M. Y. Hassan, and F. Hussin, "Residential electricity time of use (ToU) pricing for Malaysia," in 2014 IEEE Conference on Energy Conversion (CENCON), Johor Bahru, pp. 429-433, 2014.

[8] T. H. Oh, M. Hasanuzzaman, J. Selvaraj, S. C. Teo, and S. C. Chua, "Energy policy and alternative energy in Malaysia: Issues and challenges for sustainable growth-An update," Renewable and Sustainable Energy Reviews, vol. 81, pp. 3021-3031, 2018.

[9] A. Poullikkas, "A comparative assessment of net metering and feed in tariff schemes for residential PV systems," Sustainable Energy Technologies and Assessments, vol. 3, pp. 1-8, 2013.

[10] A. Poullikkas, G. Kourtis, and I. Hadjipaschalis, "A review of net metering mechanism for electricity renewable energy sources," International Journal of Energy \& Environment, vol. 4, no. 6, pp. 975-1002, 2013.

[11] L. C. S. Rocha, G. Aquila, E. d. O. Pamplona, A. P. d. Paiva, B. G. Chieregatti, and J. d. S. B. Lima, "Photovoltaic electricity production in Brazil: A stochastic economic viability analysis for small systems in the face of net metering and tax incentives," Journal of Cleaner Production, vol. 168, pp. 1448-1462, 2017.

[12] L. Ramirez Camargo et al., "Technical, Economical and Social Assessment of Photovoltaics in the Frame of the Net-Metering Law for the Province of Salta, Argentina," Energies, vol. 9, no. 3, pp. 133-154, 2016.

[13] A. Lazdovska and D. Jaunzems, "Case analysis in Latvia on involvement of end users in energy system," Energy Procedia, vol. 128, pp. 423-430, 2017.

[14] A. Zahedi, "A review on feed-in tariff in Australia, what it is now and what it should be," Renewable and Sustainable Energy Reviews, vol. 14, no. 9, pp. 3252-3255, 2010.

[15] G. C. Christoforidis et al., "Assessing policies for photovoltaic net-metering in Greece," Med Power 2014, Athens, pp. 1-8, 2014.

[16] A. I. Nikolaidis and C. A. Charalambous, "Hidden financial implications of the net energy metering practice in an isolated power system: Critical review and policy insights," Renewable and Sustainable Energy Reviews, vol. 77, pp. 706-717, 2017.

[17] J. T. Dellosa, "Financial payback of solar PV systems and analysis of the potential impact of Net-Metering in Butuan City, Philippines," in 2015 IEEE $15^{\text {th }}$ International Conference on Environment and Electrical Engineering (EEEIC), Rome, pp. 1453-1458, 2015.

[18] Y. Yamamoto, "Pricing electricity from residential photovoltaic systems: A comparison of feed-in tariffs, net metering, and net purchase and sale," Solar Energy, vol. 86, no. 9, pp. 2678-2685, 2012.

[19] R. H. G. Tan and T. L. Chow, "A Comparative Study of Feed in Tariff and Net Metering for UCSI University North Wing Campus with 100 kW Solar Photovoltaic System," Energy Procedia, vol. 100, pp. 86-91, 2016.

[20] "Grid Parity \& Displaced Cost," 2020. [Online]. Available: https://www.seda.gov.my/feed-in-tarif-fit/grid-paritydisplaced-cost/.

[21] Sustainable Energy Development Authority of Malaysia, "Guidelines of Solar Photovoltaic Installation on NEM Scheme," 2017. [Online]. Available: http://seda.gov.my.

[22] P. Celvakumaran, V. K. Ramachandaramurthy, S. Padmanaban, K. Padmanathan, A. Pouryekta, and J. Pasupuleti, "Technical constraints of integrating net energy metering from the Malaysian perspective," in 2018 IEEE PES AsiaPacific Power and Energy Engineering Conference (APPEEC), Kota KInabalu, pp. 757-762, 2018.

[23] "Tenaga Nasional Berhad," 2019. [Online]. Available: Pricing \& Tariffs. Available: https://www.tnb.com.my/residential/pricing-tariffs.

[24] Homer Energy, "Total Net Present Cost," 2019. [Online]. Available: https://www.homerenergy.com/products/pro/docs/3.11/total_net_present_cost.html. 
[25] "Malaysia Short Term Interest $\quad$ Rate," $2020 . \quad$ [Online]. Available: https://www.ceicdata.com/en/indicator/malaysia/short-term-interest-rate.

[26] HOMER "Annualized Cost,” 2019. [Online]. Available: https://www.homerenergy.com/products/pro/docs/latest/annualized_cost.html.

[27] A. Ponniran, N. A. Mamat, and A. Joret, "Electricity profile study for domestic and commercial sectors," International Journal of Integrated Engineering, vol. 4, no. 3, pp. 8-12, 2012.

\section{BIOGRAPHIES OF AUTHORS}

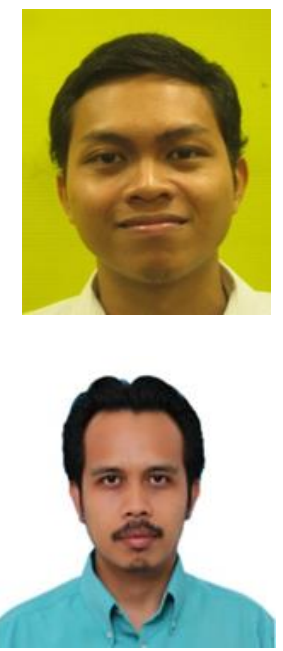

Abdul Hafiz Razali is a student at Universiti Teknologi Malaysia (UTM). He received the bachelors' degree (B.Eng.) in Electrical Engineering from Universiti Teknologi Malaysia (UTM) in 2017. Currently he is pursuing his Master study at Universiti Teknologi Malaysia.

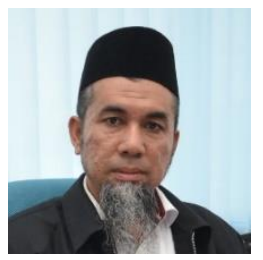

Ir. Md Pauzi Abdullah is an Associate Professor at the School of Electrical Engineering, Faculty of Engineering, Universiti Teknologi Malaysia (UTM). He is currently the Director at the Centre of Electrical Energy Systems (CEES), Institute of Future Energy (IFE), UTM. He received the bachelors degree (B.Eng) in Electrical \& Electronic Engineering from Universiti Tenaga Nasional (Uniten), Malaysia in 2002, masters degree (M.Sc) in Electrical Power Engineering and doctorate degree (Ph.D) from University of Strathclyde, Glasgow, United Kingdom in 2003 and 2008 respectively. His research interests include power systems analysis, systems security, deregulated electricity market and demand-side management. Currently, he is the Chair-Elect for IEEE Malaysia Section (2019-2020).

Dr Mohammad Yusri Hassan is a Professor at School of Electrical Engineering, Faculty of Engineering, Universiti Teknologi Malaysia (UTM). He obtained his B.Eng. in Electrical and Electronic Engineering from University of Strathclyde, United Kingdom in 1988, M.Eng in Electrical Power Engineering from Universiti Teknologi Malaysia in 1994 and $\mathrm{PhD}$ in Power System Economics from University of Strathclyde, United Kingdom in 2004. He has wide experiences in the area of energy consultancy. He was involved in the "National Energy Conservation Study" under the Ministry of Energy Telecom and Post, Malaysia (METP) in 1993.

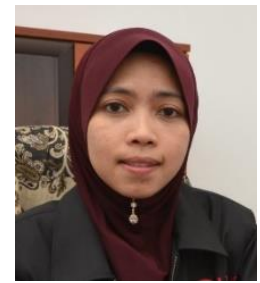

Dr. Dalila Mat Said is a Senior Lecturer at Centre of Electrical Energy Systems, School of Electrical Engineering, Faculty of Engineering, Universiti Teknologi Malaysia (UTM). She obtained her B.Eng. in Electrical Engineering in 2000, M.Eng in Electrical Engineering in 2003 and PhD in Power Quality in 2012 from Universiti Teknologi Malaysia. She has an experience within the area of power quality consultancy. She was involved in the Power Quality Baseline Study in a Peninsular Malaysia (2010-2013) under the Energy Commission of Malaysia. Her research interests are power quality and power system measurement and monitoring.

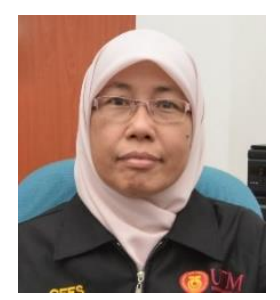

Faridah Hussin is a Senior Lecturer at School of Electrical Engineering, Faculty of Engineering, Universiti Teknologi Malaysia. She received her B.Eng. in Electrical and Electronic Engineering from University of Strathclyde, United Kingdom in 1987 and M.Eng in Electrical Power Engineering from Universiti Teknologi Malaysia in 1990. Her research interests are Deregulated Electricity market and energy efficiency. 